\title{
Uma análise da produção de significados para Álgebra Linear e a formação do professor de Matemática
}

Vitor Rezende Almeida

Prefeitura de Juiz de Fora, Colégio Tiradentes da Polícia Militar

xyvitor@gmail.com

\section{Cristiane de Andrade Mendes}

Universidade Federal de Juiz de Fora (UFJF)

Cristiane_andrade_mendes@yahoo.com.br

\section{Resumo}

Este artigo é um recorte da pesquisa na qual investigamos quais são as características da disciplina Álgebra Linear para que seja considerada um Curso de Serviço para uma Licenciatura em Matemática. Ao longo do texto direcionaremos a discussão para a entrevista que realizamos com um dos participantes da investigação sobre o que ele poderia dizer sobre uma tarefa de transformação linear e sobre sua experiência com o curso de Álgebra Linear em sua formação acadêmica. Sua entrevista teve como objetivo refinar nosso olhar sobre as possíveis contribuições da disciplina Álgebra Linear para a prática profissional do futuro professor de matemática e para nos auxiliar na construção das características da disciplina com a finalidade de repensar a formação profissional a partir das disciplinas de conteúdo matemático. A leitura da produção de significados foi desenvolvida a partir da perspectiva proposta pelo Modelo dos Campos Semânticos.

Palavras-Chaves: Educação Matemática. Formação de Professores. Curso de Serviço. Modelo dos Campos Semânticos. Álgebra Linear.

\section{An analysis of the production of meanings for Linear Algebra and the formation of the Mathematics teacher}

\begin{abstract}
This article is a research cut in which we investigate the characteristics of the Linear Algebra discipline to be considered a Service Course for a Degree in Mathematics. Throughout the text we will direct the discussion to the interview that we conducted with one of the participants of the investigation on what he could say about a task of linear transformation and his experience with the course of Linear Algebra in his academic formation. His interview aimed to refine our view on the possible contributions of the Linear Algebra discipline in the professional practice of the future teacher of mathematics and to help us in the construction of the characteristics of the discipline with the purpose of rethinking the professional formation from the disciplines of mathematical content. The reading of the production of meanings was developed from the perspective proposed by the Semantic Fields Model.
\end{abstract}


Keywords: Mathematical Education. Teacher training. Course of Service. Semantic Fields Model. Linear Algebra.

\section{Introdução}

Em nossa dissertação de mestrado (ALMEIDA, 2013) buscamos responder à questão de investigação: quais características que deve possuir a disciplina Álgebra Linear para que ela seja considerada um Curso de Serviço para uma Licenciatura em Matemática? Além dessa proposta de investigação, desejávamos desenvolver uma proposta de ensino do conteúdo Transformações Lineares para a formação matemática de estudantes da Licenciatura em Matemática, entendendo a disciplina Álgebra Linear como um Curso de Serviço.

Para a investigação das possíveis características da disciplina Álgebra Linear para que ela seja considerada um Curso de Serviço para uma Licenciatura em Matemática, foram propostas duas ações: inicialmente, realizamos uma entrevista com alunos de um curso de pós-graduação em uma universidade pública brasileira, com a intenção de obter informações relacionadas à produção de significados para a noção de transformações lineares em Álgebra Linear e sobre a formação matemática dos sujeitos de pesquisa. Em um segundo momento, projetamos, executamos e realizamos uma leitura de uma proposta da disciplina Álgebra Linear, com ementa livre, realizada na modalidade de Seminário, na mesma universidade pública, para alunos de Licenciatura em Matemática.

As informações obtidas em nossas análises das entrevistas nos forneceram subsídios para elaboração de um Seminário de Álgebra Linear e a produção de um material didático para o professor de Matemática que leciona Álgebra Linear para uma Licenciatura em Matemática. ${ }^{1}$

Utilizamos em nossa pesquisa a noção do termo Curso de Serviço no sentido proposto por Silva (2011), entendido como disciplinas matemáticas que tem o foco na formação do professor de matemática e que, portanto, não se limitam a desenvolver exclusivamente conteúdo matemático, se propondo intervir, também, em sua formação didático-pedagógica.

No estudo de Almeida (2013) foram realizadas entrevistas com três participantes da pesquisa. Entretanto discutiremos aqui a entrevista que realizamos com o participante de pseudônimo André. Assim, neste artigo, estaremos direcionando nossa atenção para a leitura e análise dessa entrevista.

Na próxima seção iremos enunciar algumas características do modelo epistemológico que orientou nossa pesquisa e as análises das entrevistas.

\footnotetext{
${ }^{1} \mathrm{O}$ texto completo pode ser encontrado em Almeida (2013)
} 


\section{O Modelo dos Campos Semânticos}

O Modelo dos Campos Semânticos (MCS) foi caracterizado por Lins como sendo

[...] uma simples, ainda que poderosa, ferramenta para pesquisa e desenvolvimento na educação matemática [...] para guiar práticas de sala de aula e para habilitar professores a produzir uma leitura suficientemente fina, assim útil, do processo de produção de significados em sala de aula. (LINS, 2001, p. 59)

E mais recentemente, fortalecendo sua crença de que o MCS é exatamente uma ferramenta, Lins caracterizou o modelo como constituído por um pequeno número de noções e nas relações entre elas. "O MCS só existe em ação. Ele não é uma teoria para ser estudada, é uma teorização para ser usada" (LINS, 2012, p. 11).

Com a intenção de esclarecer ao leitor algumas dessas noções do MCS, iremos apresentar três noções centrais encontradas no Modelo: objeto, significado e conhecimento. Segundo Lins,

um objeto é, no MCS, qualquer coisa sobre a qual uma pessoa está falando, seja ela "concreta" - por exemplo, uma cadeira em frente a mim - ou "simbólica" - por exemplo, letras em um pedaço de papel. Significados são, no MCS, o que uma pessoa efetivamente diz de um objeto em uma dada situação (dentro de uma atividade); não é tudo o que ele/ela poderia eventualmente dizer sobre essa coisa. E conhecimento é, no MCS, algo que uma pessoa realmente afirma e no qual acredita, junto com a justificação que a pessoa tem para acreditar naquela afirmação e para enunciá-la. (LINS, 2004, p.4, tradução nossa)

Lins denotou a noção de campo semântico como sendo "um processo de produção de significado, em relação a um núcleo, no interior de uma atividade” (LINS, 2012, p.17). Em outras palavras, talvez menos técnicas, um campo semântico

[...] é como se fosse um jogo no qual as regras (se existem) podem mudar o tempo todo e mesmo serem diferentes para os vários jogadores dentro de limites; que limites são estes, só saberemos a posteriori: enquanto a interação continua, tudo indica que as pessoas estão operando em um mesmo campo semântico. (LINS, 2012, p.17)

Utilizamos a noção de campo semântico para articular os processos de produção de conhecimento, produção de significados e constituição de objetos, pois é no interior de campos semânticos que se produzem conhecimento e significados e, sendo assim, objetos são constituídos.

Ainda segundo o MCS, "o núcleo de um campo semântico é constituído por estipulações locais, que são, localmente, verdades absolutas, que não requerem, localmente, justificação" (LINS, 2012, p. 26, grifo nosso).

Sendo assim, ao colocarmos o Modelo "em ação", tivemos a oportunidade de realizar uma leitura da produção de conhecimentos e de significados dos sujeitos participantes de nossa pesquisa 
com embasamento teórico e epistemológico. Em particular, o MCS fundamentou a análise da entrevista com André e com os demais participantes da pesquisa.

\section{A Metodologia}

Nossa pesquisa caracteriza-se como sendo uma abordagem qualitativa de investigação, conforme proposto por Bogdan e Biklen (2013). A análise que desenvolveremos a seguir toma como base a produção de significados do participante da pesquisa coletada a partir da sua resolução de uma tarefa proposta e de uma entrevista.

Buscando coerência com a nossa preocupação com a formação matemática do professor de Matemática em relação às disciplinas consideradas de cursos de conteúdo matemático, em particular a Álgebra Linear, esta entrevista teve como objetivo refinar nosso olhar sobre as possíveis contribuições da disciplina Álgebra Linear na prática profissional desses professores.

Os participantes da entrevista foram três alunos de um curso de pós-graduação em Educação Matemática de uma universidade pública brasileira, que haviam acabado de cursar um segundo curso de Álgebra Linear².

A entrevista foi elaborada de forma semiestruturada e constou de duas fases. Na primeira fase, que aconteceu aproximadamente uma semana antes da entrevista, foram enviadas aos participantes da pesquisa duas tarefas sobre o conteúdo específico de Álgebra Linear (a tarefa 1 era sobre Espaços Vetoriais e a tarefa 2 sobre Transformações Lineares), com a intenção de que eles as resolvessem e reenviassem suas resoluções. A escolha de enviar as questões aos participantes se justificava por dois motivos: primeiro, por nossa dificuldade em disponibilizar um momento presencial com os envolvidos, para que as tarefas fossem resolvidas e, segundo, pela possibilidade de criar neles uma maior autonomia e propiciar um maior tempo para reflexão em suas resoluções.

Após receber as resoluções dos participantes, realizamos uma leitura da produção de significados dos registros. As questões propostas são por nós consideradas familiares e não-usuais, no sentido proposto por Silva (2003, p. 53):

Familiar, no sentido de permitir que as pessoas falem a partir daquele texto e, nãousual, no sentido de que a pessoa tenha que desprender um certo esforço cognitivo na direção de resolvê-lo. O fato de a tarefa ser não-usual tem como objetivo nos permitir - enquanto professores ou pesquisadores - observar até onde a pessoa pode ir falando. [...] É importante ressaltar que a crença de que uma tarefa seja familiar e não-usual está presente apenas nas expectativas do pesquisador através do seu

\footnotetext{
${ }^{2}$ Os participantes da pesquisa cursaram pela primeira vez a disciplina Álgebra Linear em suas respectivas Licenciaturas.
} 
entendimento dos sujeitos envolvidos e do contexto onde o problema será aplicado, pois, não há nada que garanta tal crença.

As duas tarefas propostas aos sujeitos de pesquisa foram:

\section{Quadro 1 - Tarefas sobre Álgebra Linear propostas aos participantes}

\section{TAREFA 1:}

A respeito de um conjunto definido como $\mathrm{W}=\left\{(\mathrm{x}, \mathrm{y}, \mathrm{z}) \in \mathrm{IR}^{3} ; \mathrm{x}+\mathrm{y}=0\right.$ e $\left.\mathrm{z}=0\right\}$, responda:

(a) É possível exibir infinitos pares de elementos de W, cuja soma resulta no vetor nulo de $I R^{3}$ ?

(b) Podemos afirmar que W é um subespaço de $I R^{3}$, com as operações usuais de adição e multiplicação por escalar, sobre o corpo dos Reais?

\section{TAREFA 2:}

Investigue se é possível existir uma transformação linear de $I R^{3} \mathrm{em} I R^{2}$, tal que seu núcleo seja gerado pelo vetor $(1,-1,0)$.

Fonte: Dados presentes na pesquisa de Almeida (2013)

Em nossa pesquisa analisamos apenas a tarefa 2, pois ela está relacionada especificamente com a noção de transformação linear.

A justificativa da escolha da tarefa 2 deve-se a vários fatores. Inicialmente, devido ao fato de que o próprio enunciado da tarefa foi estruturado em um formato não convencional, induzindo o participante da pesquisa a uma investigação e não em buscar um algoritmo de resolução. Segundo, a tarefa tem uma ligação direta com a tarefa 1 proposta aos sujeitos, visto que o vetor que gera o núcleo da transformação linear é exatamente uma base para o subespaço envolvido na tarefa 1 . Outro motivo da escolha é o fato de essa tarefa não apresentar somente uma solução, visto que é possível exibir infinitas transformações lineares que satisfazem à condição imposta. Por fim, nessa tarefa, consideramos que os participantes da pesquisa são convidados a produzir significados em relação a vários conceitos centrais relacionados às transformações lineares, como definição de núcleo de uma transformação linear; a construção de um lei de formação da suposta transformação linear conhecendo-se apenas o que ela faz com os vetores da gerados por $(1,-1,0)$; o uso do teorema do núcleo e da imagem em relação a uma transformação linear; as noções de base e dimensão de uma espaço vetorial; e as propriedades de uma transformação linear. Após o reenvio das duas tarefas resolvidas pelos participantes da pesquisa, elaboramos algumas perguntas sobre as soluções apresentadas. 
A segunda fase da entrevista consistiu, em primeiro momento, em uma conversa com os participantes sobre os pontos considerados centrais nas resoluções das duas tarefas propostas. Em um segundo momento, foi aplicado um questionário oral ${ }^{3}$, com a intenção de identificar quais seriam as possíveis contribuições das disciplinas de conteúdo matemático na formação dos professores de Matemática e as influências de sua formação acadêmica em sua prática profissional, em particular em relação à disciplina Álgebra Linear.

As questões propostas no questionário tiveram como característica principal não antecipar a resposta dos entrevistados. Buscamos introduzir nossos temas de interesse ao longo da entrevista por meio de perguntas que permitissem ao entrevistado falar a estrutura curricular de sua formação na licenciatura em Matemática, sobre as disciplinas cursadas, sobre as influências das disciplinas de conteúdo matemático em sua prática profissional e sobre as metodologias de ensino de seus professores ao longo de sua graduação.

De forma geral, cada uma das três entrevistas durou em torno de 50 minutos, foram integralmente gravadas em áudio e posteriormente transcritas. Não tivemos problemas com horários e disponibilidade, visto que conseguimos propor aos participantes horários e locais para realizar as entrevistas que não alterassem suas rotinas profissional e acadêmica.

Nas seções seguintes serão descritas as análises da produção de significados de André.

\section{Uma Leitura da Produção de Significados de André}

O sujeito de pesquisa André tinha no momento da entrevista tinha 31 anos, cursou a Licenciatura em Matemática no período de março de 2000 até dezembro de 2006 em uma universidade pública no Estado de Minas Gerais. Em sua prática profissional, atuava lecionando Matemática para o Ensino Médio e Superior em escolas públicas e privadas de Minas Gerais. André comentou sobre sua maneira de operar e os passos de sua resolução da tarefa:

André: Primeiro que eu olhei pra ver se eu ia conseguir alguma transformação. Se bem que a pergunta é essa, né. Se é possível ter a transformação, tal que o núcleo tá. Então primeira coisa que eu fiz foi ver como é que se daria esse núcleo aí. Então eu escrevi o núcleo aqui né. Gerado por $(1,-1$ e 0$)$, então, são todos os vetores da forma (x, -x e 0), reais, tais que a transformação vai levar no vetor nulo. Aí, é, é difícil explicar como é que eu fiz isso aqui cara, eu só sei que eu bati o olho nesse negócio e eu acho que a transformação que vai dar é essa aqui, uma das que vão dar é essa daqui. Porque eu pensei o seguinte, bom já que tem que levar o $\mathrm{R}^{3}$ no $\mathrm{R}^{2}$, aqui, seria um par ordenado e aí eu precisava de ter um zero aqui e de ter um zero aqui (apontando para a primeira e para a segunda coordenadas). Então o que que acontece, como zero é o próprio zero eu já coloquei o $\mathrm{z}$ aqui e como o x é o oposto do y eu peguei

\footnotetext{
${ }^{3}$ A versão completa das questões do questionário oral encontra-se em Almeida (2013).
} 
a soma dos dois e coloquei aqui, oh. Poderia, inclusive, ser o contrário aqui né? $\mathrm{x}+\mathrm{y}$ e o $\mathrm{z}$ depois, mas, eu bati o olho aqui e falei, vou colocar este daqui e vai dar certo.

Figura 1 - Registro escrito de André - Tarefa 2

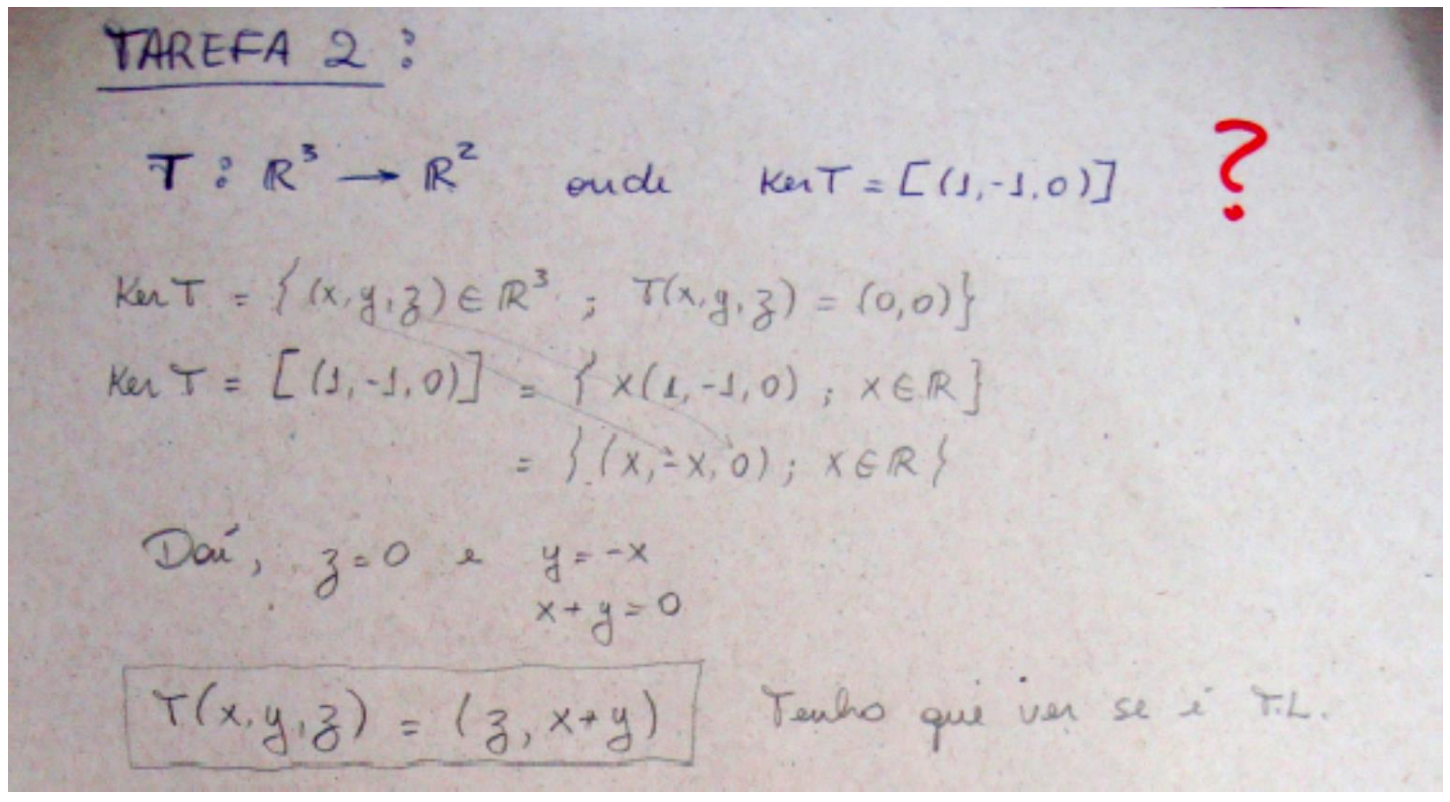

Fonte: Fragmento de pesquisa

Consideramos, em nossa leitura, que André produziu significados na direção de obter a lei de formação para candidata à transformação linear T de uma forma intuitiva, apenas observando as características que cada coordenada do vetor genérico do espaço vetorial do domínio da transformação $\mathrm{T}$ deveria ter em relação à condição imposta pela tarefa, isto é, que o núcleo fosse gerado pelo vetor $(1,-1,0)$. Buscando uma justificação para a produção de significados de André em relação à construção da lei de formação da transformação T, tivemos o diálogo:

Pesquisador: Então explica melhor como que você montou a transformação em si. Como é que se deu esse, você falou que bateu o olho e montou.

André: Sim.

Pesquisador: A transformação. Mas, assim o que te levou a ter esse insight, vamos dizer assim, de optar por ser a primeira coordenada o z e a segunda coordenada $\mathrm{o} x+\mathrm{y}$ ?

André: $\mathrm{Ah}$, na verdade, essa ordem aqui não tem pra mim, ela não tem muita, muito significado, assim, poderia ser $\mathrm{o} x+\mathrm{y}$ aqui na abscissa e o z na ordenada, aqui, não ia fazer diferença, ia dar zero, zero do mesmo jeito. Mas é porque como eu já vi que o z era zero e a primeira é o zero, eu já coloquei logo o que vai ser zero, então. Então pra garantir aqui é zero, e aí depois eu coloquei $\mathrm{o} x+\mathrm{y}$ aqui, porque o x e o y são opostos, eu só pensei isso, já 
que $\mathrm{x}$ é oposto do y então eu coloco $\mathrm{x}+\mathrm{y}$, já que são opostos vai zerar quando eu somar.

Pesquisador: Já que essa soma vai resultar em zero, você optou por colocar a soma na segunda coordenada.

André: Ahã.

Em suas palavras, André sugere que, apesar de ter obtido uma lei de formação específica para a candidata à transformação linear, ele acredita que aquela não é a única solução que poderia ser encontrada com as condições impostas na tarefa. Além disso, podemos observar que André trabalha com as estipulações locais relacionadas à definição de par ordenado (abscissa e ordenada), propriedades relacionadas à distributividade e associatividade, às operações de adição entre vetores e à multiplicação de um vetor por escalar. Após enunciar a lei de formação da relação $\mathrm{T}$ de $\mathrm{IR}^{3} \mathrm{em} \mathrm{IR}^{2}$, André se mostrou preocupado em mostrar que tal relação era uma transformação linear de $\mathrm{IR}^{3} \mathrm{em}$ $\mathrm{IR}^{2}$.

André: Aí depois que eu montei isso, eu falei eu só vou conferir se é uma transformação linear, porque eu já vi que qualquer vetor que tiver essa cara vai levar no vetor nulo, agora só tem, mas só tem que conferir se vai ser uma transformação linear. É, por isso, que eu demonstrei aqui.

Em nossa leitura da produção de significados de André, vemos que ele acreditava que qualquer vetor da forma $(\mathrm{x},-\mathrm{x}, 0)$ é levado no vetor nulo. Entretanto, não podemos afirmar se ele observou somente que os vetores dessa forma são levados no vetor nulo. Isto é, ele preocupou-se com a existência de outros vetores que também são levados no vetor nulo do IR ${ }^{2}$.

Figura 2 - Registro escrito de André - Tarefa 2

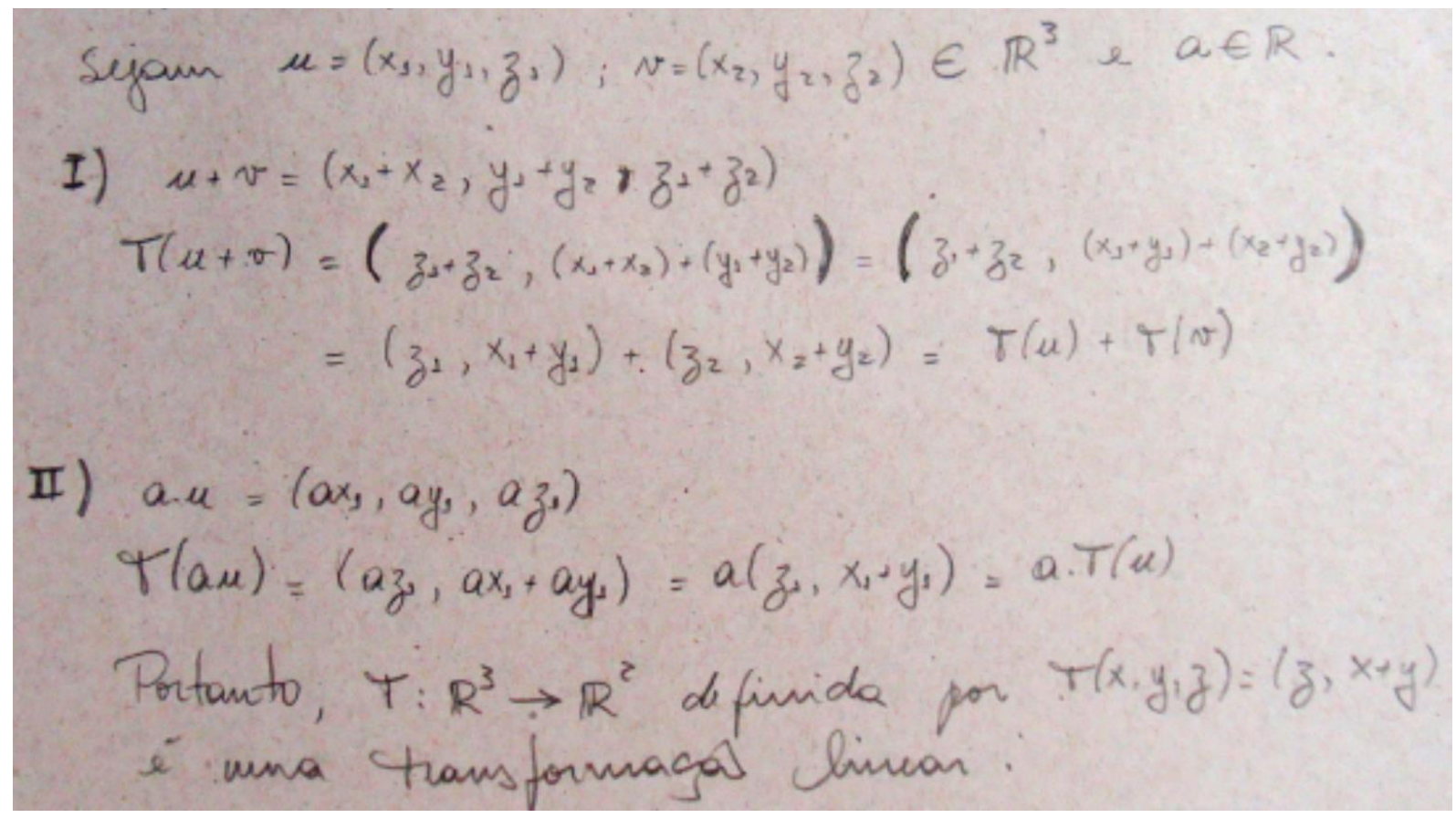

Fonte: Fragmento de pesquisa 
André definiu vetores u e v em $\operatorname{IR}^{3}$ e mostrou que a transformação em questão satisfazia às condições impostas para que ela fosse considerada uma transformação linear de $\mathrm{IR}^{3}$ em IR $\mathrm{IR}^{2}$.

Além disso, André sentiu a necessidade de justificar que a transformação linear obtida admitia realmente o núcleo gerado pelo vetor $(1,-1,0)$ para afirmar que a transformação era uma solução para a tarefa. A justificação para essa sua crença-afirmação foi:

Figura 3 - Registro escrito de André - Tarefa 2

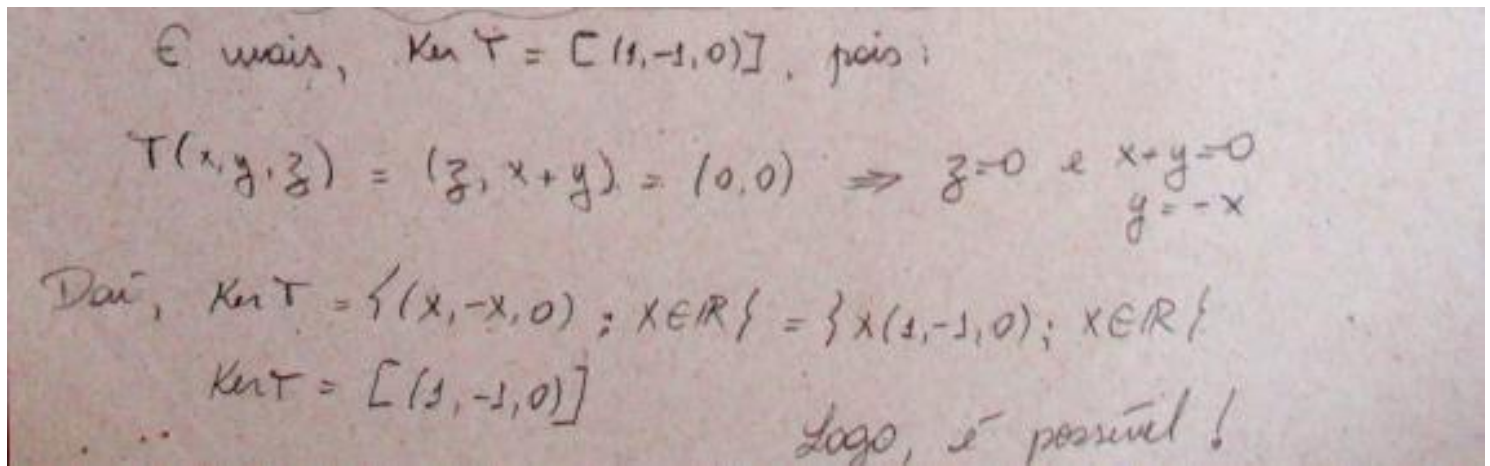

Fonte: Fragmento de pesquisa

Quando questionado sobre a possibilidade de determinar uma transformação $\mathrm{T}$ de outra forma, André afirmou que aquela era a única forma que ele via para solucionar o problema.

Pesquisador: É porque você pegou uma transformação qualquer e tentou depois, ver se ela é linear. Bom, será que toda transformação só teria essa forma de fazer, você teria que "chutar" uma transformação?

André: Eu não pensaria em outra coisa não. Eu pensaria nisso aqui mesmo.

Para finalizar o primeiro momento da entrevista, André foi perguntado a respeito das possíveis dificuldades que ele encontrou ao resolver a questão e em relação aos conceitos utilizados em sua resolução. Ao ser questionado sobre isso, ele diz:

André: Eu não vou falar que ela é difícil, mas eu também não vou falar que ela é tão simples quanto a número um. A questão que eu tive que pensar um pouco mais. Apesar de que, ao passo que eu fui fazendo, aí na hora que chegou aqui eu falei assim ah, beleza, eu acho que essa função aqui vai dar certo. Essa transformação aqui vai dar certo. Mas, ela não é uma questão tão, pra mim, simples quanto a número um. Pra mim, ela tem um nível de dificuldade um pouco maior, você tem que saber o que que é núcleo, por exemplo.

Pesquisador: Então completa aí pra nós, quais os conceitos que você usou aí, que você acha que sejam mais?

André: Transformação linear, a questão do núcleo, a questão do que que significa levar do $\mathrm{IR}^{3}$ no $\mathrm{IR}^{2}$, a questão de um vetor gerando, um vetor gera, um vetor gerando aqui um núcleo, ela tem inclusive, pra mim, pelo menos, tem mais coisa que a número um. Evidenciando assim no enunciado. 
Observamos nas falas de André que ele, ao resolver a tarefa, isto é, ao tentar determinar uma

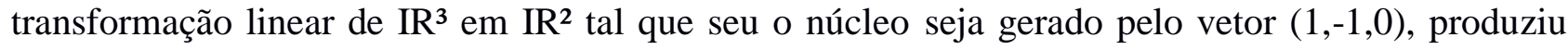
significados na direção de "levar" o IR ${ }^{3}$ no IR $^{2}$. André afirmou que, nas tarefas propostas, estavam envolvidos vários conceitos centrais de todo o curso de Álgebra Linear.

\section{Dialogando com André}

Terminado o diálogo inicial a respeito da solução da tarefa, o foco da entrevista se voltou para o questionário sobre as possíveis contribuições das disciplinas de conteúdo matemático, em particular a disciplina Álgebra Linear, em sua formação, para a formação dos professores de Matemática e sobre a influência de sua formação acadêmica em sua prática profissional.

Ao ser questionado, de uma forma geral, sobre as possíveis influências das disciplinas de conteúdo matemático em seu curso de Licenciatura, André afirmou:

André: Cara, assim, a verdade mesmo, é que são poucas as disciplinas que a gente faz na graduação e vira e fala assim, eu entendi esse negócio. Se você me perguntar qualquer coisa sobre Cálculo I, eu vou te falar, mas a verdade, na realidade é que a gente vai fazendo as disciplinas num sabe muito bem pra que que aquilo serve, também não existem esclarecimentos da parte dos professores, do porquê daquilo. Então você vai fazendo, você vai fazendo prova e você esquece daquilo. Um dia, se você precisar, você vai voltar e vai estudar.

Para André, as disciplinas de conteúdo matemático eram cursadas por ele sem um sentido. Segundo ele, basicamente o que se produzia durante os cursos era uma mera reprodução do que cairia na prova e o papel durante a disciplina era o de conseguir a média para ser aprovado e pronto. Essa afirmação pode ser percebida na seguinte fala:

André: [...] Então, assim, mas a grande maioria, e eu me incluo, nessa maioria, eu fiz Análise com o intuito de passar. Passei, tchau e benção. Álgebra II, por exemplo, a mesma coisa, eu não lembro quase nada de Álgebra II, não lembro mesmo.

Quando questionado sobre a disciplina Álgebra Linear:

Pesquisador: Então, vamos supor, uma disciplina de Álgebra Linear. Então você tá querendo dizer que se você não tivesse feito essa disciplina, você acha que você seria hoje o mesmo professor que você é?

André: Da graduação que você diz?

Pesquisador: É. Não tivesse feito na graduação, Álgebra Linear. Você acha que você seria e teria a mesma formação, o mesmo formato de aula?

André: Não. Eu acho que não. Porque, tipo assim, você vai vendo o que é e o que não é. De repente, tem um aspecto do professor que você olha e fala assim, isso eu nunca vou fazer com o meu aluno, esse tipo de metodologia eu nunca vou adotar, porque eu já tô vendo 
que não vai dar certo, esse tipo de postura também. Agora é difícil falar, se eu nunca tivesse visto Álgebra Linear será que minha postura teria mudado? A verdade é que eu só vi sistema linear em Álgebra Linear, por exemplo, aquela questão de regra de Cramer, sistema possível determinado, indeterminado que eu já tinha visto no Ensino Médio aquilo não fazia muito sentido, pra mim, tomou sentido quando eu fiz Álgebra Linear. Então, possivelmente, se eu não tivesse visto Álgebra Linear, por exemplo, continuaria até hoje sem sentido, e eu reproduziria esse sem sentido, e o meu aluno, também, pra ele não faria sentido algum.

Em um primeiro momento, vemos que a metodologia e a postura do professor que leciona a disciplina são levadas fortemente em consideração. Para André, vivenciar uma metodologia que "não deu certo" em um curso de Álgebra Linear serve como uma possibilidade de aprender o que não fazer com seus futuros alunos. Já em relação aos tópicos relacionados à Álgebra Linear, vemos que André acredita que as disciplinas de conteúdo matemático podem oferecer ao futuro professor esclarecimentos sobre alguns elementos da matemática do matemático, de ampliar a forma de produzir significados para aquelas noções, como ele citou em relação aos sistemas de equações lineares.

Ao ser questionado sobre os tópicos da Álgebra Linear que ele não iria trabalhar no Ensino Médio, André se mostrou indiferente sobre sua importância direta, mas acredita que indiretamente esses conteúdos podem enriquecer sua prática profissional. Entretanto, ele não foi capaz de justificar essa afirmação.

Pesquisador: [...] a parte de Espaços Vetoriais, de Transformações Lineares é algo que você não utiliza, por exemplo, no Ensino Médio. Se você não tivesse feito essa parte então?

André: Se eu não tivesse feito isso, eu nem saberia que isso existia.

Pesquisador: Você acha que não mudaria em nada a sua prática profissional?

André: Provavelmente não. Até porque eu não utilizo estes conceitos né. É, diretamente.

Pesquisador: E indiretamente?

André: Indiretamente você acaba usando, né. É tudo estrutura algébrica uai.

Pesquisador: Me dá um exemplo de como você usa isso indiretamente?

André: [Após pausa para pensar] Quando você próprio fala de matrizes, por exemplo, sistema linear, você tá trabalhando tudo isso, né. Essa questão do espaço vetorial, a questão das matrizes, esse tipo de coisa. Eu não sei explicar muito bem, porque eu também nunca parei pra pensar nessas coisas né.

Uma preocupação que se mostrou constante nas falas de André foi em relação à postura do professor ao lecionar uma disciplina de conteúdo matemático. André considerava a falta de esclarecimento, por parte de aluno, de como seria a disciplina como um ponto agravante e que muito o incomodava. Além disso, ele retorna a sua afirmação que, durante sua graduação, o importante era ser aprovado na disciplina e não descobrir os porquês das coisas. Entretanto, ao fazer as mesmas 
disciplinas, só que agora em um curso de pós-graduação, o foco mudou. Vemos nas falas de André, após cursar um segundo curso, uma preocupação com a reflexão a respeito dos conteúdos matemáticos e não mais com a aprovação nas disciplinas. Ele diz:

André: [...] O grande problema é que eu enquanto aluno, não sei qual é esse porquê, os professores que dão essas disciplinas também não sabem o porquê dessas coisas. Eles podem até saber "n" aplicações da Álgebra Linear no Ensino Fundamental no Ensino Médio, em qualquer nível de Ensino. Mas, isso não é colocado pro aluno. Nunca um professor chegou pra mim e falou, ó gente nós vamos começar a ver Álgebra Linear aqui hoje, é uma disciplina, eu vou mostrar aqui pra vocês o cronograma da disciplina e isso e isso aqui a gente vai poder usar futuramente nisso, naquilo outro, isso vai fazer uma conexão com isso. [...] E, é claro, que não é tirando totalmente a responsabilidade do ombro dos alunos, mas nem os alunos têm essa conduta de buscar o porquê das coisas [...]. E eu também era assim, lógico. Eu tava preocupado em passar, em terminar logo e começar a trabalhar [...]. Mas, quando eu vim pro Mestrado, e eu decidi fazer a disciplina de Cálculo, eu queria fazer o Cálculo com outros olhos, [...] Então, depois que você passa você sai da graduação, os seus olhos mudam, lógico, lógico que mudam [...].

Outro ponto considerado por nós importante na fala de André é em relação à forma como é oferecido o curso de Álgebra Linear e em relação às possíveis aplicações do conteúdo da Álgebra Linear em sua prática profissional. Para ele, os conteúdos matemáticos são oferecidos de forma fragmentada, dificultando ao aluno uma visão abrangente a respeito da matemática envolvida nas disciplinas.

André: Eu acho que assim, nem tudo vai ser, nem todas as coisas serão imediatamente aplicadas, algumas coisas, elas serão pré-requisitos, é, por exemplo, você vai falar disso, amanhã você vai falar daquilo outro, e aí, no dia de amanhã, quando você tiver condição de abranger a sua visão do todo, então aquilo ali tudo amarrado vai ganhar um sentido então, mas o problema é que a nossa conduta não é levada a isso, a impressão que dá é que você vai pegando pedacinhos e vai, tudo fragmento e vai guardando sempre em gavetas separadas, você nunca coloca numa gaveta, a gaveta da Álgebra Linear, não você vê o que, sistema aí dentro de sistemas tem lá, regra de Cramer, regra disso, regra daquilo, tal, tal, tal, aí você passa. Espaço vetorial, aí você vem, subespaço vetorial, aí você chega em núcleo, você vai passando, você vê anel, você vê corpo, você vê... várias estruturas, só que você vai jogando tudo cada um pra uma gaveta. E, depois você não consegue amarrar isso, então não é que isso é culpa dos professores, ou é culpa da disciplina, eu acho que é difícil achar um culpado, mas fato é que da maneira como a gente vê ou como a gente faz, ou como o ensino da graduação se dá, ela não contribui pra que o aluno veja o todo, ele sempre vai estancando as coisas, os professores também não adotam uma postura de tentar orientar e os alunos também adotam também uma postura de não buscar essa orientação, porque pra ele é muito mais cômodo só tirar a nota. 
Ao ser perguntado sobre em que esse modelo de aula influenciou sua formação e prática profissional, André se considera aliviado por não engessar suas aulas. Para ele, o importante é ser capaz de produzir significados diversos sobre o conteúdo a ser trabalhado em sala de aula e não em sua capacidade de reprodução do conteúdo.

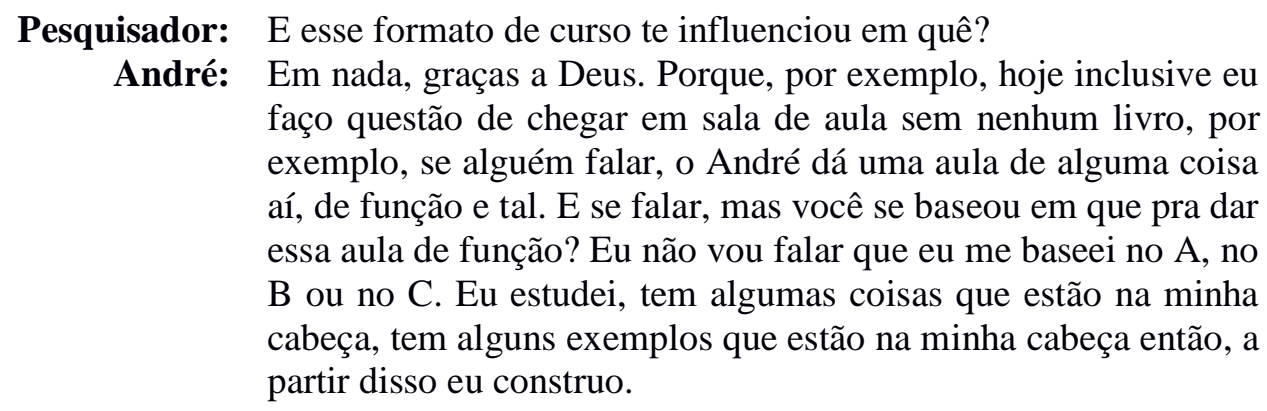

\section{Considerações Finais}

Após nossa leitura da produção de significados de André e de suas considerações sobre os questionamentos da entrevista, ficou evidente para nós a influência do modelo tradicional de ensino em sua formação e em suas concepções em relação à sua prática profissional. Entretanto, fundamentado em nossa leitura de suas respostas, para André, as disciplinas de conteúdo matemático, incluindo neste grupo a Álgebra Linear, foram apenas obstáculos que deveriam ser ultrapassados em sua formação. Para André, o que mais o influenciou nestas disciplinas foi a postura metodológica e profissional de seus professores, o que ele não queria assumir e nem reproduzir.

A produção de significados de André possibilitou uma reflexão sobre como deveria ser a disciplina Álgebra Linear, voltada para alunos de uma licenciatura em Matemática. Além disso, nossa leitura da produção de significados de André nos forneceu uma direção para as possíveis características para um Curso de Serviço de Álgebra Linear para a Licenciatura em Matemática ao indicar, principalmente, o que não foi satisfatório em sua formação.

\section{Referências}

ALMEIDA, V. R. Álgebra Linear como um Curso de Serviço para a Licenciatura em Matemática: o Estudo das Transformações Lineares. 2013. 161p. Dissertação (Mestrado em Educação Matemática) - Instituto de Ciências Exatas, Universidade Federal de Juiz de Fora, Minas Gerais, 2013.

BOGDAN, R. C.; BIKLEN, S. K. Investigação Qualitativa em Educação. Uma introdução à teoria e aos métodos. Portugal: Porto Editora, 2013.

LINS, R. C. O modelo teórico dos campos semânticos: uma análise epistemológica da álgebra e do pensamento algébrico. Revista Dynamis, Blumenau, v.1(7), p.29-39, abr./jun., 1994. 
LINS, R. C. The production of meaning for Algebra: a perspective based on a Theoreticall Model of Semantic Fields. In: R. Sutherland et al. Perspectives on School Algebra. Netherlands: Kluwer Academic Publishers, 2001.

LINS, R. C. O Modelo dos Campos Semânticos: estabelecimentos e notas de teorizações. In:

Modelo dos Campos Semânticos e Educação Matemática: 20 anos de História. ANGELO, C. L. et al. São Paulo: Midiograf, p. 11, 30. 2012.

SILVA, A. M. Sobre a Dinâmica da Produção de significados para a Matemática. 2003. 243 p. Tese (Doutorado em Educação Matemática) - IGCE/UNESP: Rio Claro, 2003.

SILVA, A. M. Um Curso de Serviço para a Licenciatura em Matemática. XIII Conferência Interamericano de Educação Matemática. Recife: CIAEM, p.1-7, 2011. 